\title{
Impactos Ambientais na Vertente Oeste da Serra de São José, Rio Grande do Norte, Brasil
}

\section{Environmental Impacts in the West Slope of the São José mountain range, Rio Grande do Norte, Brazil}

\author{
José Ilânio Chaves $\otimes^{1}$; Jorge Luís de Oliveira Pinto Filho $\otimes^{2}$; Vandygna Emiliana Chaves da Silva $\oplus^{3}$
}

${ }^{1}$ Mestre em Planejamento e Dinâmicas territoriais no Semiárido pela Universidade Estadual do Rio Grande do Norte, Campus de Pau dos Ferros, Rio Grande do Norte, +558481689296, ilanio chaves@ hotmail.com; ${ }^{2}$ Doutor em Desenvolvimento e Meio Ambiente pela Universidade Federal do Rio Grande do Norte, Campus Central, Natal, Rio Grande do Norte, jorge.filho@ufersa.edu.br; ${ }^{3}$ Graduada em Geografia pela Universidade Estadual do Rio Grande do Norte, Campus de Pau dos Ferros, Rio Grande do Norte, vandygnaemiliana@gmail.com

\begin{tabular}{l} 
A R T I G O \\
\hline Recebido: 02/09/2019 \\
Aprovado: 04/12/2019 \\
\\
\hline Palavras-chave: \\
Degradação ambiental \\
Geossistema \\
Unidade serrana \\
Planejamento ambiental.
\end{tabular}

Key words:

Environmental degradation

Geossistema

Mountain drive

Environmental planning

\begin{abstract}
R E S U M O
A análise integrada dos componentes ambientais, principalmente no semiárido nordestino, é uma ação primordial para analisar os processos atuantes na modelagem e na estrutura do território. O objetivo deste trabalho é expressar o quadro ambiental da vertente Oeste da Serra de São José, Rio Grande do Norte, através do diagnóstico dos recursos naturais da região e identificação dos impactos que se distribuem sobre sua extensão ambiental. Para isso, faz-se uso do método sistêmico por conceber essas unidades ambientais como complexos organizados em que são estabelecidos processos dinâmicos que modelam a paisagem e redefinem seus espaços. Acrescenta ainda a realização de levantamentos descritivos e exploratórios (campo), representações cartográficas na escala de 1:1 mil acerca de seus elementos naturais e formas de usos desenvolvidos, com a finalidade de compreender os impactos que se distribuem nesse território. Observou-se mudança significativa na paisagem da vertente serrana, pela descaracterização de sua vegetação que vem conduzindo a uma instabilidade de algumas áreas de seu relevo, já que este ambiente apresenta uma taxa altimétrica considerável, com a presença de escarpas bem definidas. Para tanto, faz-se necessário traçar diretrizes de planejamento ambiental que minimizem os impactos que possam estar ocorrendo nesse território, possibilitando a manutenção e a conservação de todos os seus recursos.
\end{abstract}

A B S T R A C T

The integrated analysis of the environmental components, especially in the semi-arid Northeast is paramount to analyze the processes active in modeling and structure of the territory. The aim of this work is to express the environmental framework of the West slope of the Sierra de São José, Rio Grande do Norte, through the diagnosis of the natural resources of the region and identification of impacts that are about your environmental extension. For that, use of systemic method for designing these environmental complex organized in units that are established dynamic processes that shape the landscape and redefine their spaces. Adds the completion of descriptive and exploratory surveys (field), cartographic representations in the range of 1:1 thousand about their natural elements and uses developed forms, with the purpose of understanding the impacts that are distributed in this territory. There has been significant change in the landscape of the mountain slope, the distortion of your vegetation that is leading to an instability of some areas of your relief, since this environment presents a significant altimetric rate with the presence of cliffs right set. To do so, if necessary draw environmental planning guidelines that minimize the impacts that may be occurring in that territory, making possible the maintenance and upkeep of all its resources.

com efeitos adversos para os ecossistemas (CRISPIM; SOUZA, 2016).

Os processos de evolução das paisagens variam de acordo com as características ambientais de cada domínio natural, além das diversas formas de uso e ocupação do solo (BASTOS, especia dos recursos naturais ocasionados pelo homem, em

\section{Revista Verde}

ISSN 1981-8203

Pombal, Paraíba, Brasil v. 15 , n.1, jan.-mar, p.62-72, 2020

doi: 10.18378/rvads.v15i1.6993

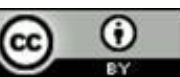


2012). Sendo assim, quando trata de paisagens, Ab’Sáber (2003) destacou a importância de entendê-las como heranças de processos fisiográficos e biológicos que possuem marcas nitidamente justificadas pelas variações climáticas do Quaternário.

A paisagem, no Brasil, apresenta em toda sua extensão territorial um grande e diversificado mostruário ecológico (FREIRE, 2007), reestabelecendo dessa forma, uma diversificada configuração geoambiental. No Nordeste brasileiro, determinadas formas de relevo se destacam em meio ao grande domínio da Depressão Sertaneja, por muitas vezes com características singulares no contexto semiárido regional. Dentre estas formas, destacam-se os maciços cristalinos, que são caracterizados por feições residuais com grandes dimensões, atingindo cotas elevadas (entre 500 e 1000m), sendo geralmente formados por processos de erosão diferencial e sustentados por rochas mais resistentes ao intemperismo e a erosão em relação ao embasamento cristalino circundante (BRANDÃO, 2014).

A partir das características mencionadas, os distintos complexos paisagísticos estão sujeitos às influências antrópicas e naturais, com destaque para os desmatamentos irregulares que sequencialmente são seguidos pelas queimadas, ocupação agropecuária, processos erosivos nas encostas, degradação das nascentes, represamento irregulares, entre outros, que, em seu conjunto, comprometem a biodiversidade, gerando, assim, um processo de desequilíbrio ambiental, fatores os quais Cunha e Guerra (2000) atribuíram serem causas do manejo inadequado do solo, em que a ocupação desordenada desses ecossistemas é responsável por acelerar os processos degradacionais que comprometem sua qualidade ambiental.

Diante desse cenário, diversos estudos vêm sendo desenvolvidos com a finalidade de identificar os principais problemas em áreas semiáridas montanhosas, Molua e Lambi (2001) Klik et al. (2002), Augustine (2003), Little et al. (2003), De Jong et al. (2004), Nair (2005), Amiri (2009), Tabari e Agrajanioo (2013), Gholami et al. (2018), que discutem as problemáticas ambientais dos ecossistemas áridos nas mais diversas partes do planeta continuamente.

Em nível de Brasil, constatou-se que são vários os autores que discutem as características ambientais das unidades serranas e seus potenciais impactos, sejam eles antrópicos ou naturais, Moté et al. (2006); Amorim e Oliveira (2008); Bayle et al. (2012); Oliveira Filho (2012); Silva et al. (2012); Freitas et al. (2013); Ritter et al. (2015); Corrêa et al. (2016); Ferreira e Piroli (2016) e Braz et al. (2017) que aproximam o quadro interativo desses ambientes com a realidade vivenciada nos mais distintos ecossistemas montanhoso do país.

Em recorte da região do Semiárido, observam-se contribuições de Cunha (2011); Lima (2012); Costa (2015); Bastos e Peulvast (2016); Brasileiro et al (2016); Crispim e Souza (2016); Ribeiro e Bastos (2016); Amorim et al. (2017); Araújo e Diniz (2017); Freires et al. (2017); Martins et al (2017); Oliveira et al. (2017) e Santos e Aquino (2017) que se aportam de problemáticas ambientais em enclaves serranos de ecossistemas semiáridos como subsidio a aprofundar as principais características que atingem essas unidades regionais.

Especificamente na região sudoeste do Estado do Rio Grande do Norte, na zona semiárida do nordeste brasileiro, localiza-se a Serra de São José na microrregião de São Miguel, que vem passando por processo de uso e de ocupação do território sem planejamento prévio, ocasionando uso inadequado dos recursos naturais (QUEIROZ, 2014). Em função dos efeitos para o meio ambiente decorrentes das atividades exploratórias na Serra de São José - RN, justificamse estudos relacionados com a identificação dos impactos ambientais para determinar o quadro ambiental da área desse geossistema.

Dessa forma, para compreender melhor o processo de modificações da paisagem ao longo dos anos, faz-se necessário tecer uma análise integrada dos componentes ambientais, já que é uma ação primordial para analisar os processos atuantes na modelagem e na estrutura do território, cujo método favorece a compreensão acerca das problemáticas advindas das diferentes formas de uso e de ocupação, o qual constitui um instrumento direcionador para o planejamento e gestão ambiental desses espaços.

Portanto, o presente estudo tem como objetivo expressar o quadro ambiental da vertente oeste da Serra de São José-RN, diagnosticando os recursos naturais da região, por meio da identificação dos usos preponderantes dos recursos naturais na mesma, apontando os possíveis impactos ambientais que se distribuem ao longo de sua extensão territorial.

\section{MATERIAL E MÉTODOS}

A área em estudo localiza-se na microrregião da Serra de São Miguel, porção sudoeste do Estado do Rio Grande do Norte, zona semiárida do nordeste brasileiro, compreendendo a vertente oeste da Serra de São José, apresentando-se disposta no sentido sudoeste/nordeste abrangendo os municípios de Venha Ver a (sudoeste), Coronel João Pessoa a (oeste), Luís Gomes ao (sul) e Riacho de Santana a (leste), (Figura 01).

Figura 01: Mapa de Localização da Vertente Oeste da Serra de São José, Rio Grande do Norte, Brasil

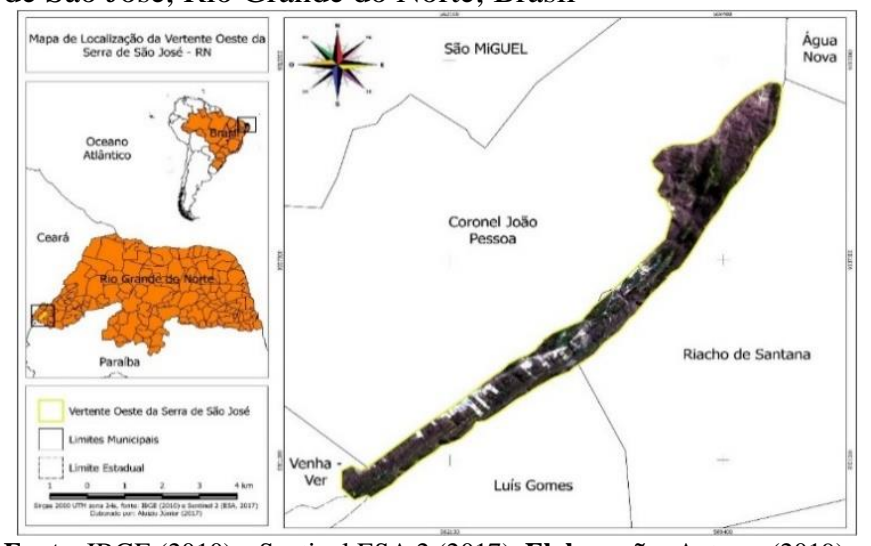

Fonte: IBGE (2010) e Sentinel ESA 2 (2017). Elaboração: Autores (2019).

\section{Procedimentos teóricos e metodológicos}

Esta pesquisa classifica-se conforme sua finalidade em descritiva (descreve as características ambientais da área de estudo) e exploratória (torna os problemas ambientais mais explícitos através da identificação das fontes geradoras). Quanto aos meios utilizados, enquadra-se como bibliográfica e de campo, através de exploração da estrutura territorial da área investigada com a finalidade de discutir as formas de usos e ocupação que possam alterar sua característica ambiental (GIL, 2006).

A execução deste trabalho abordou o método sistêmico, por considerar a paisagem como um complexo organizado de elementos naturais e antrópicos que atuam conjuntamente. Para tal compreensão, são discutidos seus aspectos geológico e geomorfológico, classes de solos e hidrografia da área, seu 
clima predominante, além de sua vegetação correspondente, relacionando-a aos usos e ocupações para melhor compreender a estrutura paisagística dessa unidade territorial.

Desta forma, o diagnóstico socioambiental e econômico da Serra de São José - RN consiste num processo sistemático que envolve as etapas apresentadas a seguir:

Para o recorte da área de estudo foi utilizado bases cartográficas georreferenciadas fornecidas pelo Instituto Brasileiro de Geografia e Estatística - IBGE (2010) e imagens de satélite do Sentinel - ESA 2 (2017), cuja resolução espacial de 10 (dez) metros possibilitou adequar sua configuração territorial e processar a espacialização geográfica de sua área através do software Quantum Gis 2.4 para uma representação aproximada de sua estrutura terrestre (CARVALHO, 2011).

Quanto à caracterização da área de estudo, processou-se um conjunto de cartas temáticas (unidades geológicas e dados geomorfológicos, classes de solos e hidrografia, além da vegetação e usos e ocupações), através de bancos de dados digitais georreferenciados fornecidos pelo Instituto Brasileiro de Geografia e Estatística - IBGE (2010), bem como os dados do livro do Zoneamento Ecológico-Econômico do Alto Oeste Potiguar - ZEE (2014), que permitiu uma ampliação de informações da estrutura dos componentes e processos atuantes no contexto da paisagem do ambiente em estudo (LIMA, 2012). Para tanto, foram usadas imagens de satélite do Sentinel - ESA 2 (2017) de resolução espacial de 10 (dez) metros, no intuito de obter uma melhor aproximação com os objetos mapeados.

No levantamento dos tipos de usos dos recursos naturais da região, foram realizados estudos de campo para averiguação da verdade terrestre, mediante técnica de observação que consubstancie uma aproximação com os objetos digitais para o conhecimento detalhado de suas características ambientais (SILVA, 2013). Assim, para uma maior precisão acerca desses usos, foram feitos registros fotográficos para representação da espacialização dos fenômenos, cuja comprovação dos elementos levantados foi possível mediante uma averiguação das imagens do Google Earth (2017).

Para identificação dos impactos ambientais da área de estudo, fez-se necessária a realização da técnica de check list (tipos de usos, formas de poluição, efeitos e consequências) (DERÍSIO, 2012), a qual permitiu uma aproximação do pesquisador com o objeto pesquisado, permitindo o conhecimento da verdade terrestre mediante usos de imagens fotográficas, as quais permitem o detalhamento da estrutura e o funcionamento desse sistema natural mediante interpretação de imagens concebidas in loco, favorecendo a investigação dos fenômenos atuantes nesse processo (SILVA, 2011).

Dessa forma, os dados foram analisados mediante o agrupamento das informações produzidas e armazenadas no banco de dados digitais sobre os elementos naturais da região. No mais foram realizadas visitas de campo com a finalidade de diagnosticar os diferentes tipos e usos da terra e suas principais fontes de degradação, para que possa contribuir com o manejo e conservação do ambiente (SILVA, 2011). Portanto, o agrupamento dessas informações foi cruzado com uma variedade de bibliografias nacionais e internacionais que abordam essas problemáticas ambientais em ecossistemas serranos, fator decisivo para nos possibilitar maior conhecimento sobre seus pressupostos.

Para subsidiar a proposição, fez-se uma análise das diretrizes ambientais da Vertente Oeste da Serra de São José, determinando seus principais usos, os impactos ambientais das atividades desenvolvidas para avaliação das formas de exploração que atingem esse espaço conforme a Lei 12.651 de 25 de maio de 2012 (BRASIL, 2012).

As variáveis abordadas nessa avaliação foram as seguintes: localização dos usuários dos recursos naturais, tipos de usos dos recursos, possíveis fontes degradantes da área de estudo e os efeitos dessa degradação. Por fim, apresentou-se um fluxograma, com a descrição das principais etapas da pesquisa conforme pode ser visto na (Figura 02).

Figura 02: Fluxograma das Principais Etapas da Pesquisa

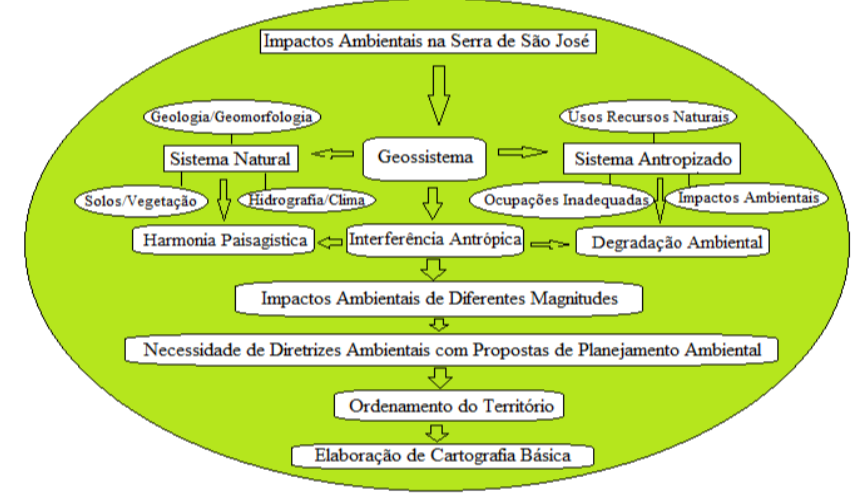

Fonte: Autores, 2019.

\section{RESULTADOS E DISCUSSÃO}

\section{Clima e vegetação}

O clima predominante da Vertente Oeste da Serra de São José classifica-se como um clima tropical chuvoso Aw' com distribuição pluviométrica anual em torno de 850-900 mm e temperaturas variando entre $26^{\circ} \mathrm{C}$ a $30^{\circ} \mathrm{C}$ (IDEMA, 2010), caracterizando-se como um clima de temperaturas amenas e com duas estações bem definidas, uma chuvosa no verão e outra seca no inverno. Sendo assim, o clima influencia a vegetação, fator este que para Odum (2015) a vegetação de uma área responde a sua dinâmica climática, sendo esta determinante para a estrutura vegetacional de determinado espaço (figura 03).

Concebe-se que a área tem uma formação vegetal do tipo caatinga hipoxerófila, com espécies próprias desses ambientes semiáridos, destacando-se pelo porte adensado na quadra chuvosa que atinge essa região (verão-outono) e uma fisionomia relativamente aberta no período de estiagem (inverno-primavera), fator que reflete a singularidade do padrão vegetacional desta porção territorial (NUNES, 2006).

Ainda no que diz respeito ao conjunto vegetacional da área de estudo, observou-se que é de porte denso em áreas com declividades acentuadas e caatinga aberta em áreas de relevo mais rebaixados, fator este que denuncia uma vegetação secundária de exploração recente.

Para fins de análises, algumas das características pertinentes a esse sistema também são percebidas quando se estuda os complexos paisagísticos das serras do JuáConceição-CE, a unidade serrana de João do Vale-RN, a serra de Baturité-CE, a expansão urbana e suas influencias sobre a vegetação na serra de Aratanha-CE, como também na subbacia hidrográfica do Riacho Santana, constituindo espaços semiáridos que vêm apresentando uma descaracterização parcial de sua vegetação. Destarte e Lima (2012) justificou que apesar da adversidade proporcionada pela semiaridez, são os usos acrescidos pela agropecuária, o extrativismo de remanescentes florestais e as ocupações urbanas desordenadas 
que vêm desafiando a estabilidade vegetacional desses territórios.

Figura 03: Mapa vegetacional da Vertente Oeste da Serra de São José, Rio Grande do Norte.

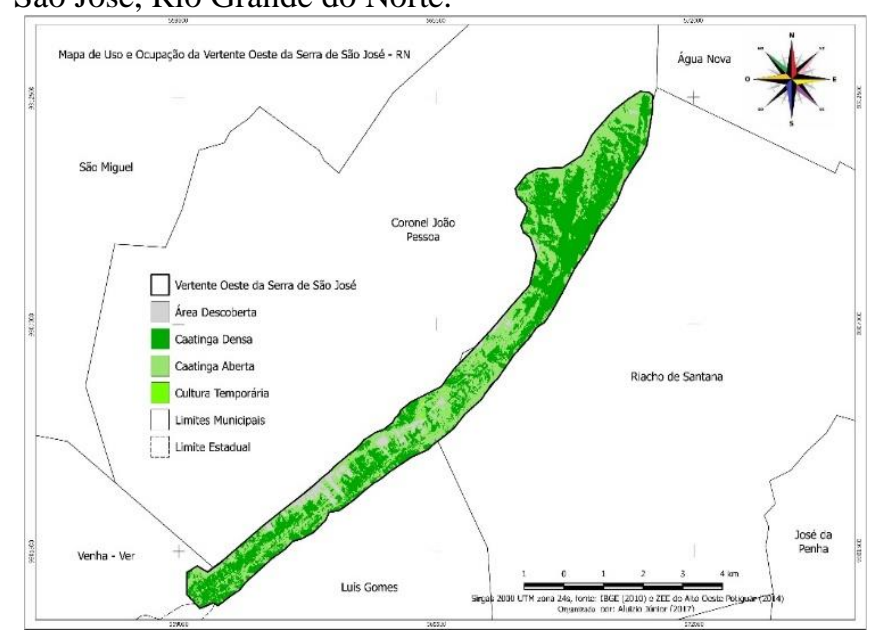

Fonte: IBGE (2010) e dados do ZEE do Alto Oeste Potiguar (2014) Elaboração: Autores (2019).

\section{Geologia e geomorfologia}

A área em estudo encontra-se inserida, geologicamente, segundo Sousa (1984) sobre a província Borborema, em meio ao domínio morfoescultural Jaguaribeano, sendo constituído por unidades geológicas que correspondem ao grupo Serra de São José e Serra de São José Quartzito, além da Suíte Serra do deserto compreendendo um mosaico de rochas ígneas metamórficas compostas predominantemente por granito e quartzito (ANGELIN, 2006). Para Rodriguez e Silva (2002), essa geologia é bem representativa do nordeste brasileiro, a qual é representada por áreas de depressão separada por uma série de serras ou chapadas que se formam no embasamento cristalino, manifestando diferentes características (Figura 04).

Em termos geomorfológicos, a área em estudo compreende o maciço residual Serra de São José (NUNES, 2006). Esse planalto, em função de sua extensão, apresenta formas distintas que se tornam perceptíveis em sua paisagem, podendo ser citados os planaltos residuais em formas convexas, planaltos residuais em formas tabulares e planaltos residuais em formas de pediplanos.

Figura 04: Mapa geológico (A) e geomorfológico (B) da Vertente Oeste da Serra de São José, Rio Grande do Norte.

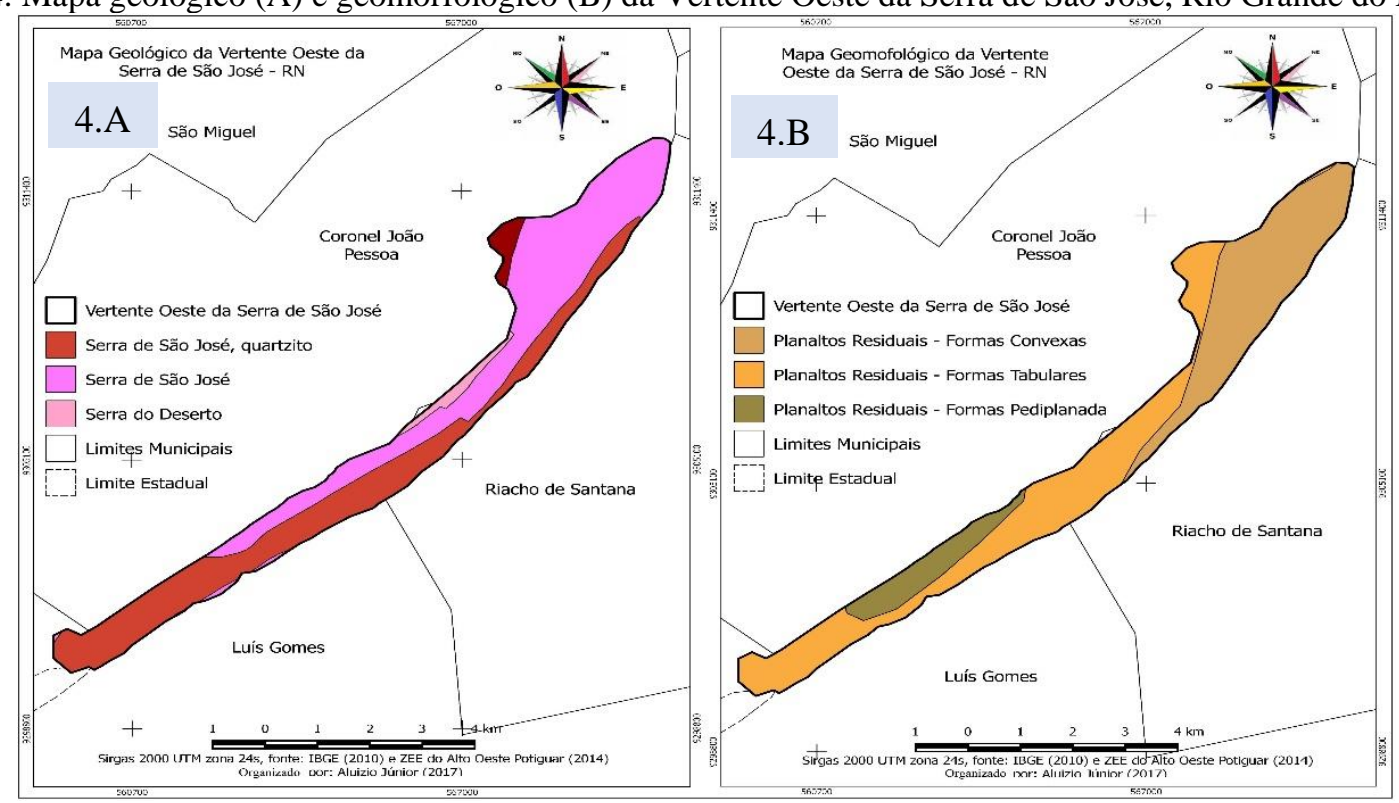

Fonte: IBGE (2010) e dados do ZEE do Alto Oeste Potiguar (2014). Elaboração: Autores (2019).

\section{Classes de solos e hidrografia}

Há predominância do argissolo vermelho-amarelo eutrófico, um solo que segundo Lepesch (2002) contém um horizonte (A) mineral, sobreposta a uma camada (B) mais argilosa, que, apesar de pouco profundo é rico em nutrientes e geralmente apresenta uma camada de cascalho sobre sua superfície (Figura 05). Dessa forma, Guerra e Cunha (2000) expõem que o solo é um elemento que interfere diretamente sobre os recursos hídricos, caso seu uso e manejo se dê de forma inadequada.

Quanto aos recursos hídricos superficiais, a área em estudo está inserida no alto curso da bacia hidrográfica ApodiMossoró, apresentando um padrão de drenagem dendrítico com forte densidade de drenagem devido à declividade da área, a qual forma uma rede de canais de $1^{\circ}$ e $2^{\circ}$ ordem que se reflete sobre seu substrato rochoso, visto que existe a variação no escoamento em função dos períodos do ano.
Em avaliação aos riscos e vulnerabilidades desse complexo serrano, observou-se ocorrência de degradação do argissolo em áreas de acentuada exploração antrópica sobre as vertentes serranas, o que Souza et al. (2008) afirmam constituir um obstáculo ao desenvolvimento sustentável, por conduzir a uma instabilidade de algumas áreas de seu relevo, já que este ambiente apresenta uma taxa altimétrica considerável com a presença de escarpas bem definidas, provocando a perda da qualidade físico-químicas desses ambientes.

\section{Tipos de uso dos recursos naturais e identificação dos impactos ambientais da área de estudo}

No desenvolvimento deste tópico, buscou-se fazer uma correlação entre os tipos de usos mais recorrentes na área em estudo com os impactos ambientais de seu meio natural, no intuito de diagnosticar as fontes de degradação que desafiam a estabilidade ambiental da Vertente Oeste da Serra de São José, 
Rio Grande do Norte. Para tanto, descreveu-se também os requisitos legais cabíveis ao disciplinamento das intervenções humanas em seu espaço, tendo em vista, serem essas leis, meios eficientes para se traçar medidas de gerenciamento para sua unidade ambiental, conforme descrito na (Tabela 01).

Figura 05: Mapa das classes de solo (A) e de hidrografia (B) da Vertente Oeste da Serra de São José, Rio Grande do Norte.

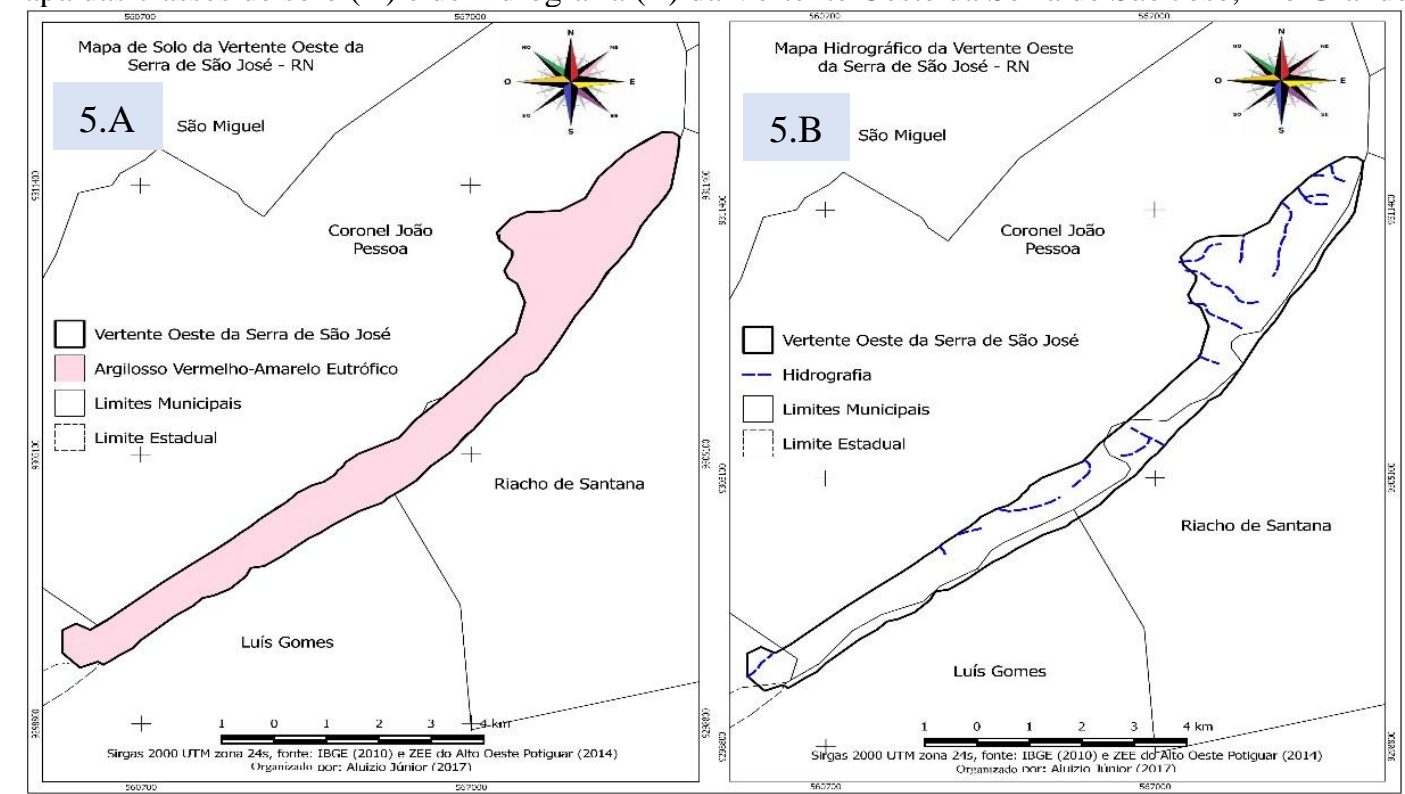

Fonte: IBGE (2010) e dados do ZEE do Alto Oeste Potiguar (2014). Elaboração: Autores, (2019).

Tabela 01. Usos, Impactos Ambientais e Aspectos Legais da Vertente Oeste da Serra de São Jose, Rio Grande do Norte.

\begin{tabular}{|c|c|c|}
\hline USOS & IMPACTOS AMBIENTAIS & REQUÍSITOS LEGAIS APLICADOS \\
\hline \multirow{4}{*}{ Agricultura } & Desmatamento & Lei $\mathrm{n}^{\circ} 12.651 / 2012$ \\
\hline & Erosão & Decreto $^{\circ} 76.470 / 1975$ \\
\hline & Queimadas & Lei $\mathrm{n}^{\circ} 6.938 / 1981$ \\
\hline & Uso de Agrotóxicos & Lei $n^{\circ} 7.802 / 89$ \\
\hline \multirow{6}{*}{ Pecuária } & Afugentamento da fauna & Lei $^{\circ} 5.197 / 1967$ \\
\hline & Desmatamento & Lei $\mathrm{n}^{\circ} 6.938 / 1981$ \\
\hline & Remoção da cobertura do solo & Decreto $\mathrm{n}^{\circ} 76.470 / 1975$ \\
\hline & Remoção da vegetação nativa & Lei $\mathrm{n}^{\circ} 12.651 / 2012$ \\
\hline & Remoção das matas ciliares & Lei $n^{\circ} 12.651 / 2012$ \\
\hline & Queimadas & Lei $\mathrm{n}^{\circ} 6.938 / 1981$ \\
\hline \multirow{3}{*}{ Obras Hídricas } & Erosão & Decreto $^{\circ} 76.470 / 1975$ \\
\hline & Assoreamento & Lei $n^{\circ} 9.433 / 1997$ \\
\hline & Degradação dos habitats & Lei $n^{\circ} 9.605 / 1998$ \\
\hline Estradas & Degradação dos Solos & Decreto $^{\circ} 76.470 / 1975$ \\
\hline Aglomerados Humanos & Degradação do meio ambiente & Lei $\mathrm{n}^{\circ} 6.938 / 1981$ \\
\hline Caça Predatória & Extinção das espécies & Lei $n^{\circ} 5.197 / 67$ \\
\hline Pesca Desenfreada & Degradação das Espécies Aquáticas & Lei $n^{\circ} 221 / 67$ \\
\hline
\end{tabular}

As condições de uso e de ocupação do solo da vertente oeste da Serra de São José são marcadas pela espacialização de um conjunto de impactos ambientais que se distribuem desordenadamente sobre toda a estrutura desse ecossistema, fatores estes que vêm contribuindo para um desequilíbrio ambiental nesta área. Quando se sabe que, atualmente, cresce o reconhecimento dos transtornos ambientais causados ao meio ambiente por atividades antrópicas inadequadas a capacidade de suporte de alguns ambientes terrestre (LITTLE et al., 2003).

Entre os impactos que se apresentam em sua paisagem, destacam-se, com maior amplitude, os desmatamentos (Figura 6.a), que se destinam atender a agricultura e a pecuária. Concomitantemente são seguidos pelas queimadas indiscriminadamente, fator que favorece a degradação do solo com processos erosivos de diferentes magnitudes (Figura 6.b), que comprometem a biodiversidade da área. Desta forma, ao atingir desordenadamente seu sistema ambiental gera consequências negativas, tornando-se questão de preocupação para todo o espaço territorial (NAIR, 2005). Observou-se, também, uma sucessividade de barramentos sobre $\mathrm{O}$ geossistema em estudo que influenciam no regime hídrico local, degradação de nascentes, ocupações irregulares sobre os mais diversos pontos da vertente, construções de estradas e, caça e pesca predatória, sendo esses fatores que atingem esse brejo de altitude, segundo Oliveira et al. (2017) de forte influência na degradação de seu sistema ambiental. 
Figura 06: Desmatamentos (A) e Processos Erosivos (B) na Vertente Oeste da Serra de São José, Rio Grande do Norte.

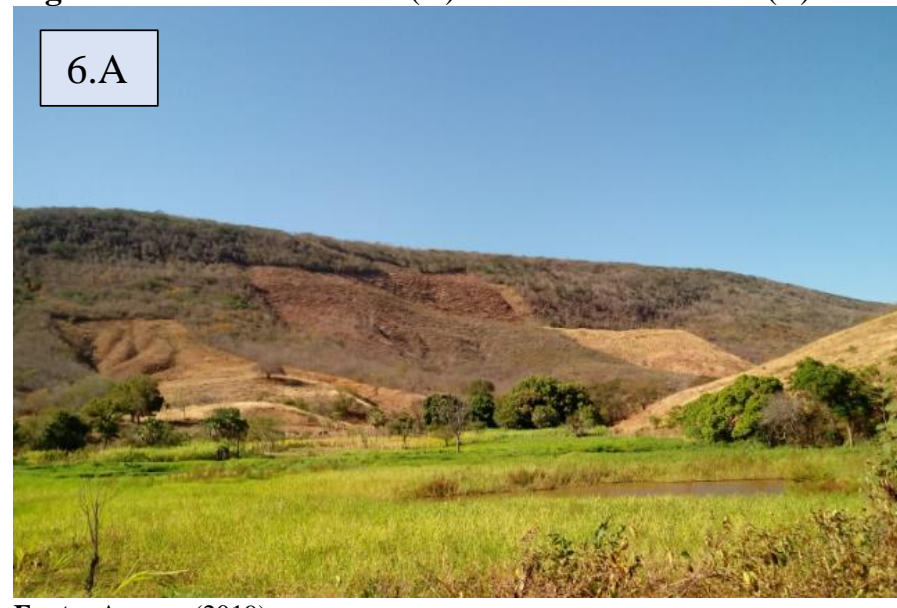

Fonte: Autores (2019).

Em relação ao desmatamento enquanto uma ação desequilibrada está associado no ambiente em estudo a práticas agrícolas rudimentares e ampliação de áreas de pastagens, para introdução de espécies exóticas, a exemplo do Capim Agropolo (Andropogon gayanus), aliado a criação de bovinos e caprinos transformam a paisagem serrana, com consequências negativas sobre todo seu sistema ambiental, quando se sabe que o uso das terras desses espaços serranos, sem planejamentos adequados, tem gerado consequências ambientais negativas para todo o geossistema (BRAZ et al., 2017). Corroborando tais resultados, Lima (2012) apontou que esses processos, que fazem parte da cultura do sertão são responsáveis pela degradação da caatinga. Diante desse cenário, observa-se que as explorações dos recursos naturais ocorrem de forma padrão no semiárido brasileiro, necessitando, dessa forma, medidas de controle ambiental.

Assim, a área em análise apresenta diversos espaços em vulnerabilidade aos processos erosivos, representando segundo Klik et al. (2002) uma forte ameaça ao desenvolvimento do recurso solo, haja visto diminuir sua fertilidade natural, seja em decorrência de fatores naturais (erosão por gravidade, erosão fluvial, erosão pluvial e erosão eólica) ou desgaste intensificados pela ação antrópica (agricultura, pecuária, estradas, obras hídricas e aglomerados humanos). Com isso, são os desmatamentos, principalmente em regiões montanhosas, que desregulam esses ambientes por proceder de usos e manejos inadequados (AMIRI, 2009), que destinados a abertura de áreas de pastagens com a finalidade de alimentar bovinos na vertente serrana compromete esse sistema, e vem conduzindo a desregulamentação da qualidade do recurso solo. Sendo assim, a sua degradação, segundo Molua e Lambi (2001), se soma ao esgotamento de sua cobertura vegetal.

Nesta perspectiva, torna-se visível uma mudança significativa na paisagem da vertente serrana, pela descaracterização de sua vegetação que vem conduzindo a uma instabilidade de algumas áreas de seu relevo, já que este ambiente apresenta uma taxa altimétrica considerável que alcança os 750 metros, com a presença de escarpas bem definidas, o que para Corrêa et al. (2016) esses índices de degradação é causa única da ausência da vegetação, necessitando, esses ambientes, de implantação de técnicas de uso e manejo adequado para manutenção de sua área, principalmente quando é sabido que a vegetação é essencial para a provisão dos serviços ecossistêmicos, funcionando como estabilizadora do ambientes.

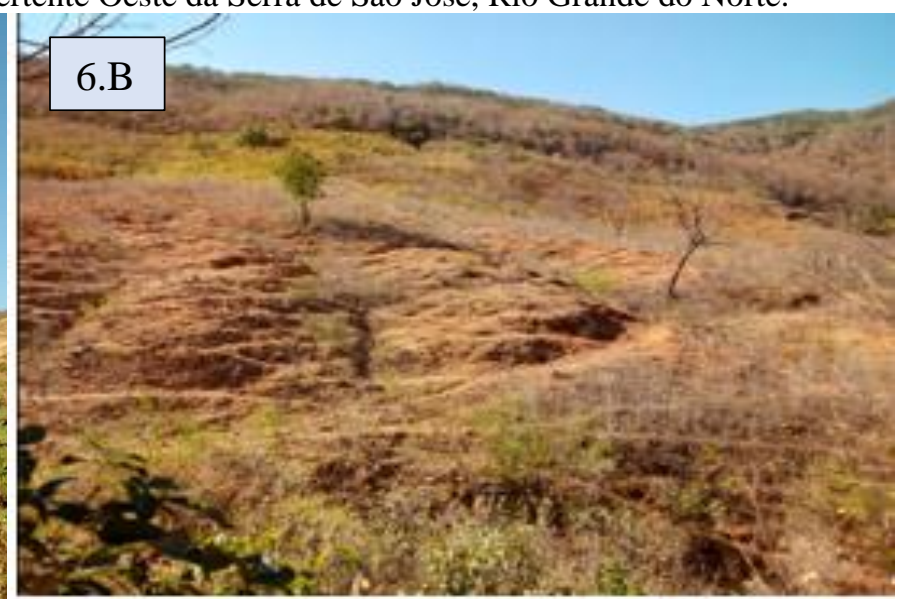

Dessa forma, Amorim et al. (2017) correlacionaram que é primordial a compreensão acerca dos fatores que moldam os processos erosivos desse ambiente, por garantir a compreensão de sua dinâmica ecossistêmica, haja vista a exploração dos recursos naturais se processarem sem que seja levada em consideração a capacidade de suporte dessa unidade ambiental.

Diante dessa mudança paisagística local, Bastos e Peulvast (2016) compreenderam que a ação antrópica tem contribuído fortemente para provocar uma forte instabilidade na vertente serrana, destacando-se um conjunto de práticas rudimentares que transformam a paisagem das encostas naturalmente instáveis em áreas de risco ambiental, quando se sabe que a vegetação é um agente protetor para a qualidade ambiental do sistema.

Após o corte da vegetação, torna-se uma prática comum executar a queimada (Figura 7.a), como uma alternativa utilizada, pelos proprietários, para limpar a área em questão. Nesse cenário, Costa (2015) apontou que essa ação desequilibra promove sérios riscos ao meio natural dos ecossistemas. Desse modo, esse processo de preparar a terra implica em ações negativas para todo o ambiente, já que desregulariza a estrutura de toda a cadeia produtiva das espécies vegetal e animal, comprometendo toda a biodiversidade desse território.

Aliado a ocorrência de queimadas nesse território, também se deve considerar a perda das propriedades físicoquímicas dos solos (Figura 7.b) desse ambiente. Nesta perspectiva, Cunha (2011) relatou que o mau uso dos recursos naturais pode contribuir, de forma expressiva, para a degradação ambiental. Assim, é sabido que as terras exploradas pela monocultura durante anos, através de técnicas de cultivos rudimentares comprometem suas condições naturais, fator que se agrava com a criação extensiva de rebanhos, provocando forte compactação e erosão e uma diminuição significativa da qualidade dos solos. Ainda sobre essa discussão, os autores Amorim e Oliveira (2008) acrescentam que os problemas ambientais que atingem essas áreas serranas são marcados pelos distintos processos que desarticulam a estrutura e funcionamento de seus sistemas naturais.

Nesse sentido, em função dos distintos fatores degradantes desse ambiente e em face de suas características semiáridas, Santos e Aquino (2017) acreditam que esse ambiente tende futuramente a apresentar processos de desertificação acentuado, já que sobre sua estrutura são conhecidos fortes impactos negativos que comprometem a qualidade ambiental desse sistema. 
Figura 07: Ocorrência de queimadas (A) e degradação dos solos (B) no ambiente da Vertente Oeste da Serra de São José, Rio Grande do Norte.

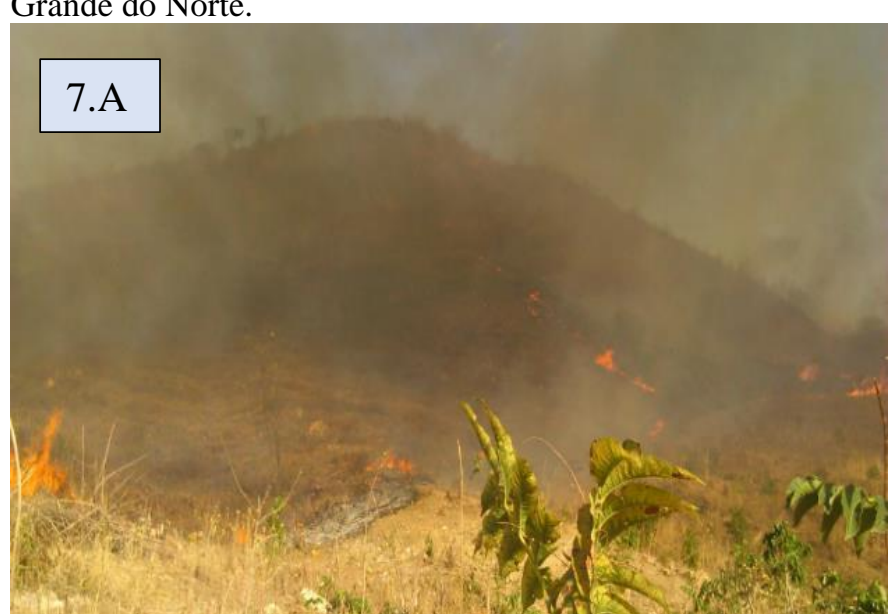

Fonte: Autores (2019).

O quadro de degradação ambiental se intensifica em decorrência da alteração da área de nascente (olho d'água) localizado sobre o sítio Coité (Figura 8.a), a qual apresenta a vertente bastante destituída de vegetação nativa para introdução do capim Agropolo (Andropogon gayanus), que vem conduzindo a diminuição significativa de sua mata ciliar, que segundo Ritter (2015) esse desmonte da mata ciliar é uma ação que busca obter novas áreas para implantação de cultivos agrícolas, ocasionando solos descobertos susceptíveis a processos erosivos, gerando perdas sobre os recursos de seu entorno.

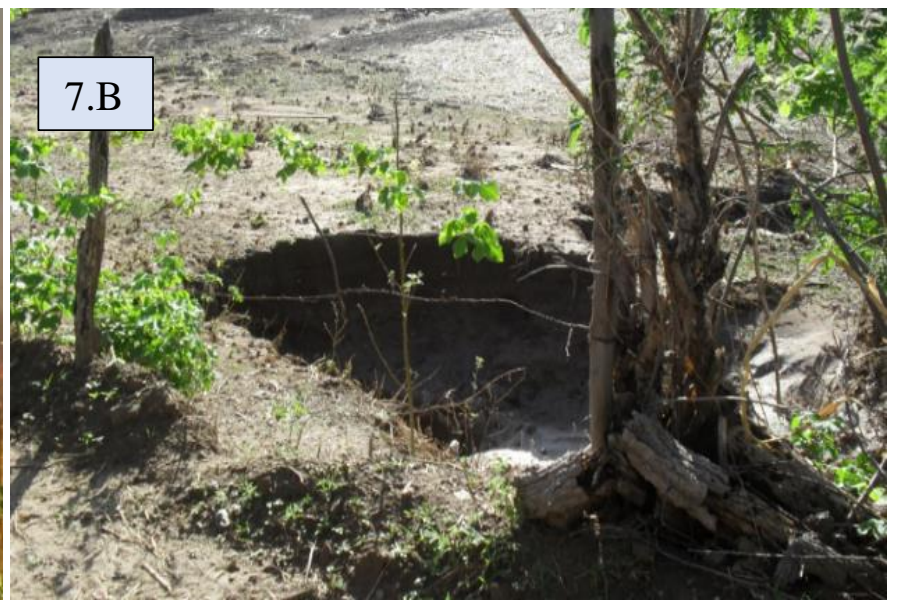

Em relação a isso, Bailly et al. (2012) demostram que a fragmentação florestal (Figura 8.b), é um processo que vem substituindo grandes áreas de vegetação nativa por outro ecossistema, provocando o isolamento dos remanescentes de floresta original. Diante desse cenário, se essas ações não forem planejadas rapidamente, poderá levar a exaustão dessas áreas, o que provocará consequências severas para todo o ambiente, levando ao entendimento de Oliveira Filho (2012) que os agravamentos dos impactos socioambientais estão relacionados ao processo desordenado de ocupação das encostas.

Figura 8: Alteração ambiental de áreas de nascentes (A) e Degradação da vegetação (B) na Vertente Oeste da Serra de São José, Rio Grande do Norte.

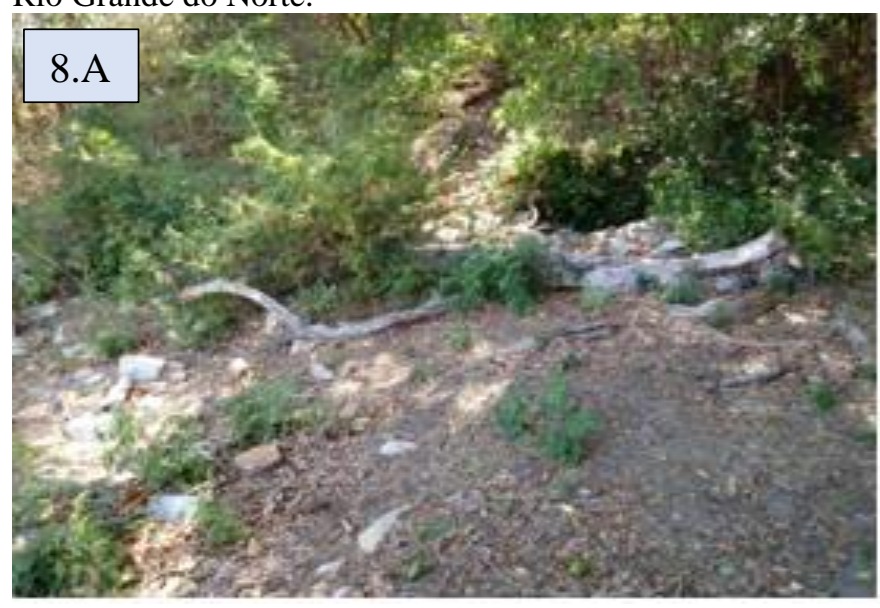

Fonte: Autores (2019).

Nesse ambiente, a degradação vem ocorrendo pela descaracterização parcial de sua vegetação, que vem comprometendo a estabilidade dessas áreas. Dessa forma, são observáveis distintos padrões espaciais de vegetação que se alternam com áreas de solos despidos de cobertura vegetacional, fator esse que representa áreas destinadas a algumas atividades antrópicas, constituindo ameaças ambientais a esses ecossistemas semiáridos (AUGUSTINE, 2003).

Nessa perspectiva, Araújo e Diniz (2017) argumentaram que, diante da devastação que atingem a cobertura vegetal das unidades serranas, algumas fontes perenes estão ameaçadas, apresentando uma gradual diminuição de seu volume d'água,

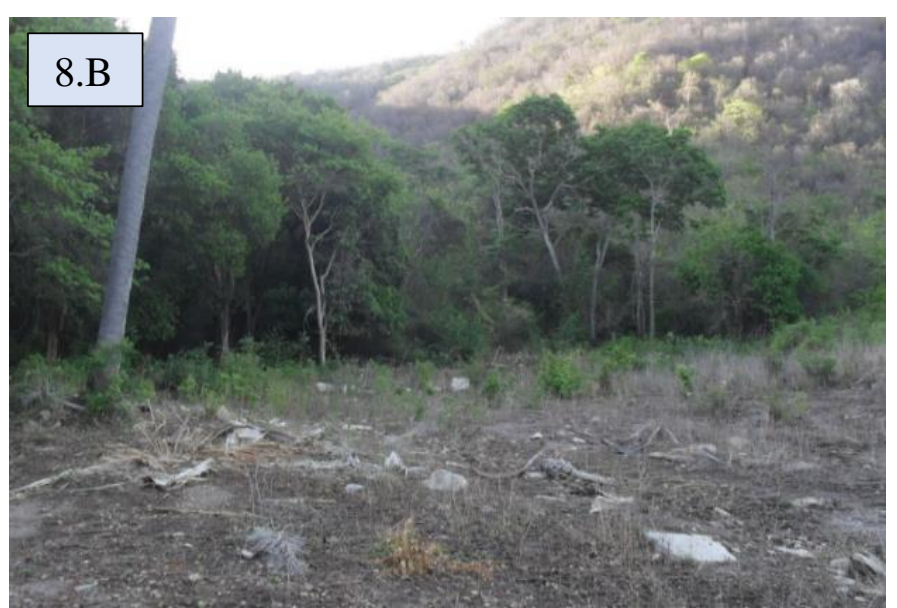

o que convém ressaltar ser um sinal provável de ressecamento da fonte num futuro próximo.

Os recursos hídricos investigados também são alterados através da existência de sucessivos barramentos (Figura 9.a) ao longo de sua extensão territorial e sobre os mais diversificados pontos da vertente serrana, atingindo inclusive áreas com declividades superiores a $500 \mathrm{~m}$ de altitude, para o qual Costa (2015) aponta ser uma prática comum no semiárido brasileiro, cuja funcionalidade visa atender as demandas dos rebanhos e algumas comunidades no período da estiagem, sendo a pesca, uma atividade praticada de forma artesanal, (Figura 9.b) e servindo ao atendimento dos interesses das famílias locais. Conforme observado em campo, esses pequenos reservatórios, 
tornam-se elementos inadequados que contribuem para gerar desequilíbrios no fluxo hídrico dos canais, modificando seus regimes regulares e refletindo uma nova dinâmica para o padrão de drenagem dessa região.

$\mathrm{Na}$ área em questão, encontramos diversos reservatórios que, se destinam a utilidades múltiplas, atendendo inclusive ao consumo humano, tornando-se propícios ao desenvolvimento econômico dessas comunidades. Diante dessa realidade, Molua e Lambi (2001) destacaram que a construção desses reservatórios, além de modificar os cursos dos rios por desregular o fluxo de drenagem regular, atinge negativamente muitas atividades humanas, desequilibrando as funções ambientais desse ambiente. Dessa forma, reconhecendo a importância das áreas montanhosas para os recursos hídricos, De Jong et al. (2004) justificaram que esses ambientes montanhosos desempenham funções importantes no balanço hídrico das bacias hidrográficas regionais.

Figura 09: Barramentos construídos no leito dos riachos serrano (A) e pesca artesanal (B) na Vertente Oeste da Serra de São José, Rio Grande do Norte.
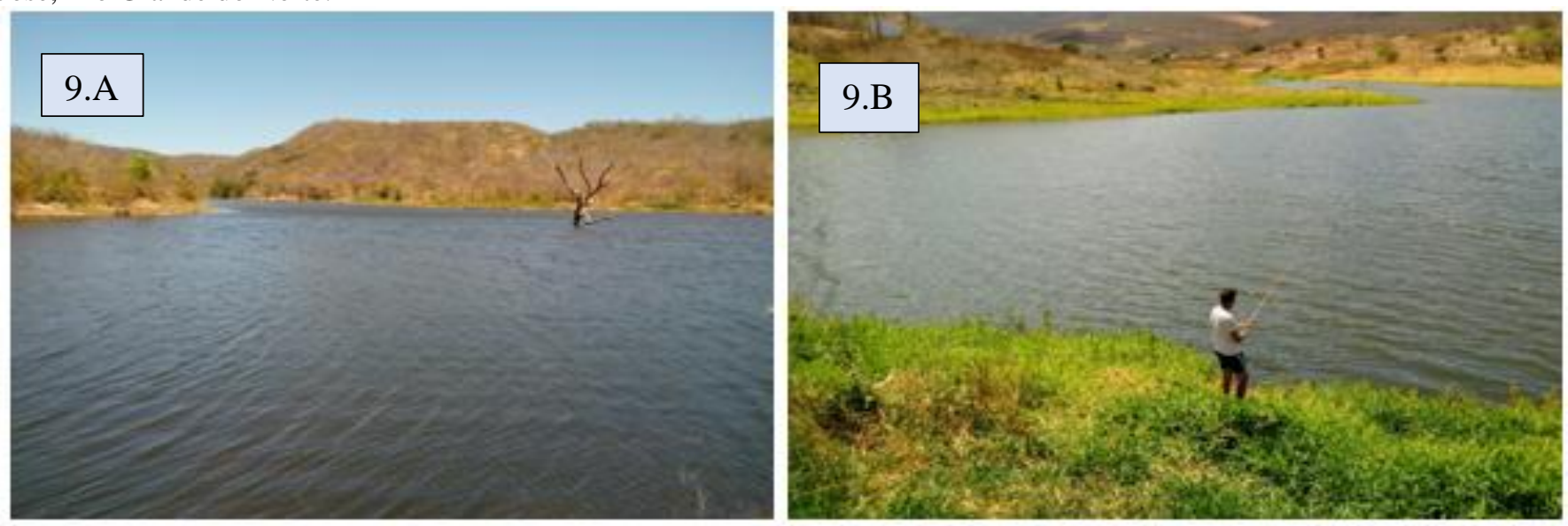

Fonte: Autores (2019).

Ao longo dessa estrutura serrana, é comum a abertura de estradas (Figura 10.a), que se destina a possibilitar acesso a algumas comunidades (Figura 10.b), que embora dispersas entre si, se localizam sobre esse maciço residual, provocando degradação sobre a estrutura do solo que agravam os problemas ambientais da área. Corroborando tal pensamento,

Freires et al. (2017) destacaram que essas trilhas que adentram a unidade serrana corroboram para desencadear problemas ambientais severos. Por não ser pavimentado, o solo exposto fica submetido aos processos erosivos, podendo incorrer em processos de deslizamentos nas encostas, em função da declividade da área e da forte densidade de drenagem.

Figura 10: Aberturas de estradas (A) e ocupações inadequadas (B) ao longo da Vertente Oeste da Serra de São José, Rio Grande do Norte.
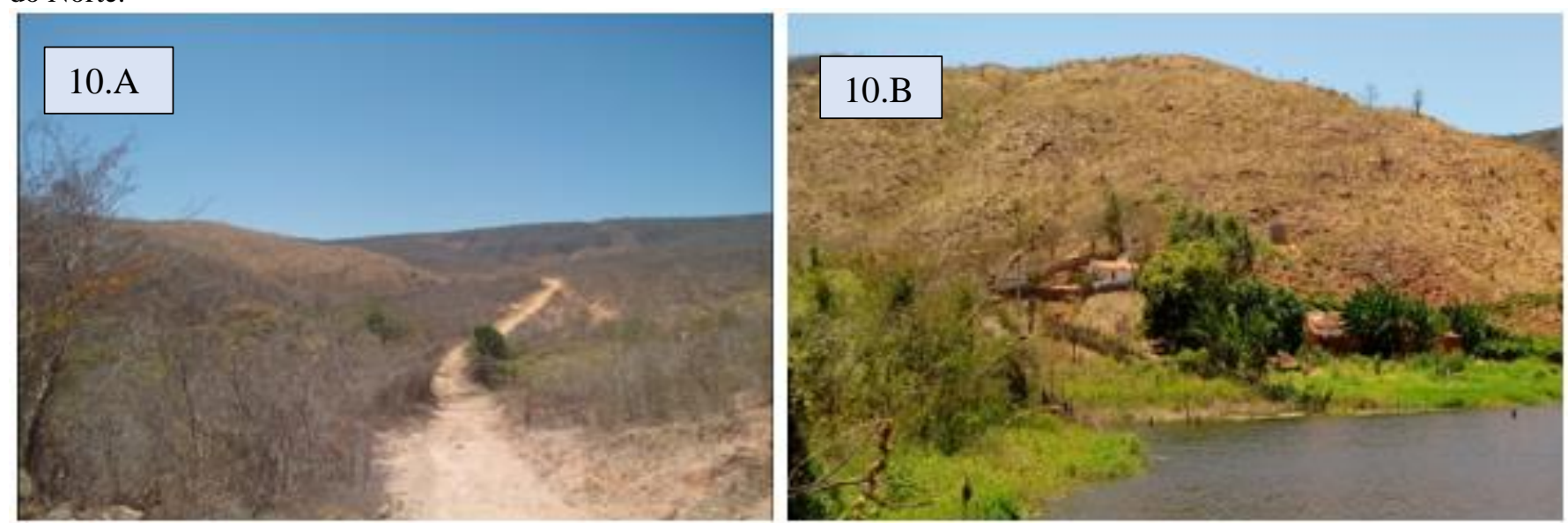

Fonte: Autores (2019).

As alterações ambientais sobre essa unidade territorial também relacionam com as ocupações inadequadas, denunciando o que segundo Moté et al. (2006) afirmaram ser um fator que se faz presente de longa data e que se mantém até os dias atuais comprometendo sua estrutura ambiental, ligada a uma agricultura rudimentar sempre associada a práticas agropecuárias. Para Silva et al. (2012), essas formas de ocupações são comuns no território investigado, necessitando de regulamentação baseada em estudos técnicos, para

prevenção de danos ambientais. Freitas et al. (2013) inseriram em suas discussões que as ocupações irregulares dessas unidades ambientais pela agropecuária são propulsoras de degradação ambiental nesses geossistema terrestres. Diante do exposto, percebe-se que as áreas analisadas apresentam forte incidência desses usos, constituindo um fator limitante para a qualidade ambiental dessa porção territorial.

Assim sendo, Crispim e Souza (2016) justificaram em suas discussões que a ocupação desordenada desses ambientes 
serranos provoca danos ambientais consideráveis, uma vez que aumenta o escoamento superficial dessas áreas em virtude da retirada da cobertura vegetal tornando-se áreas de risco para todo o complexo geoambiental.

Diante dessas formas de ocupações, Ribeiro e Bastos (2016) afirmaram que os processos degradantes do ambiente ao mesmo tempo em que são definidos como parte da dinâmica natural do ambiente ou mesmo influenciado pelas ações antrópicas, trazem consequências negativas para a população residente em seu espaço em diferentes proporções.

Corroborando com tais resultados, Martins et al. (2017) destacaram que essas áreas de preservação permanente estão sendo ocupadas por moradias e plantações de forma inadequada, não sendo respeitadas as regulamentações previstas na Lei 12, 651 de 25 de maio de 2012, no que diz respeito à conservação de sua paisagem e formas de uso e ocupação (BRASIL, 2012).

Ainda nessa linha de pensamento, Ferreira e Piroli (2016) relataram que a diversidade de usos que atingem essas unidades ambientais por meio de culturas agrícolas, as pastagens e criação de animais de forma irregular são indicadores significativos de desordenamentos ambientais que podem conduzir a processos erosivos, assoreamentos, depauperamento do solo e perda de toda a biodiversidade da área. Aliado a isso, Brasileiro et al. (2016) conceituaram que a agricultura e a pecuária, por serem atividades econômicas que advêm de tempos pretéritos nesses ambientes serranos, tornam-se uma tendência a desencadear vários problemas ambientais ao longo desse maciço residual.

Esse espaço geoambiental também apresenta áreas nas quais as intervenções humanas ainda são incipientes, com a presença de uma vegetação arbórea de porte secundário em estágio de conservação que se distribui sobre as partes altas do relevo. Com isso, nas partes mais rebaixadas predomina a vegetação arbustiva, denunciando a exploração antrópica com padrão de vegetação aberto e presença de inúmeros fragmentos de rochas na superfície. Assim sendo, Gholami et al. (2018) expõem que a capacidade de regeneração desses ambientes depende da estrutura dos microhabitats de seu núcleo ambiental em relação aos usos desenvolvidos em seu ecossistema.

Para tanto, constatou-se a existência da caça predatória, que embora se apresente de forma reduzida, torna-se uma prática comum entre alguns indivíduos desse espaço territorial, denotando risco a existência e reprodução das espécies. Isto posto, Amado (2014) enalteceu o Decreto 6.514/2008 como uma ampliação da Lei $n^{\circ}$ 9.605/1998 (Lei de Crimes Ambientais), designando no artigo 24 do referido decreto as penalidades cabíveis aos infratores que praticarem conduta lesivas contra qualquer tipo de espécies da fauna silvestre, cabendo ao órgão competente a aplicação da multa. Assim, Tabari e Agrajanloo (2013) deixaram claro que o reconhecimento das características e funções dos ambientes áridos e semiáridos, assim como o respeito as suas aptidões produtivas, são primordiais para explicar as características de sua paisagem com vista a desenvolver práticas de uso racional nesses ambientes.

Portanto, recomendam-se novas investigações da qualidade ambiental da área de estudo, envolvendo aspectos relacionados ao planejamento ambiental (elaboração de propostas para consolidação e/ou alteração parcial e/ou total da realidade) e ao gerenciamento ambiental (monitoramento das propostas), principalmente quando se sabe que não existe nenhum instrumento legal que subsidiem ações para promover sua proteção ambiental e que a conservação de seu espaço territorial se torna primordial para as interações geossistêmicas de seu núcleo ambiental.

\section{CONCLUSÃO}

Os usos no ambiente da Vertente Oeste da Serra de São José são múltiplos e diversificados, fator decisivo para alterar a complexidade paisagística dos elementos naturais desse sistema semiárido.

Assim, há a ocorrência de impactos ambientais em diversos graus de abrangências em seu meio natural, que vem propiciando vulnerabilidades no geossistema serrano, fator decisivo por acelerar a degradação de seu núcleo ambiental com severos prejuízos socioambientais para seu sistema natural.

\section{REFERÊNCIAS}

AB'SÁBER, A. N. Os Domínios de Natureza no Brasil: potencialidades paisagísticas. São Paulo, SP: Ateliê Editorial, 2003.

AMADO, F. A. T. Direito Ambiental Esquematizado. $5^{\circ}$ ed. São Paulo: Método, 2014, 1040 p.

AMIRI, F. A Model for Classification of Range Suitability for Sheep Grazing in Semiárid Regions of Iran. Islamic Azad University, Bushehr Branch. Department of natural Resources. Bushehr Iran. v.21, n.5, 2009.

AMORIM, R. F.; SILVA, F. M.; CORRÊA, A. C. B. Modelo Rampa: esboço metodológico para dimensionamento de vertentes. Revista de Geografia. v.34, n.2, 2017.

AMORIM, R. R.; OLIVEIRA, R. C. As Unidades de Paisagens como uma Categoria de Análise Geográfica: o exemplo do município de São Vicente-SP. Revista Sociedade \& Natureza. v.20, n.2, p.177-198, 2008.

ANGEliM, L. A. A.; MEDEIROS, V. C.; NESI, J. R. Programa Geologia do Brasil - PGB. Projeto Geologia e Recursos Minerais do Estado do Rio Grande do Norte. Mapa geológico do Estado do Rio Grande do Norte. Escala. 1:500.000. Recife: CPRM/FAPERN, 2006. 1mapa color

ARAÚJO, F. H. R.; DINIZ, M. T. M. Paisagem de Exceção e os Problemas Ambientais da Serra de João do Vale. In: I Congresso Nacional de Geografia Física. 2017, São Paulo. Artigo... Campinas-SP: Unicamp, 28 de junho à 02 de julho de 2017, p. 3207-3218. 10.20396/sbgfa.v1i2017.1864.

AUGUSTINE, D. J. Spatial Heterogeneity in the Herbaceous Layer of a Semi-arid Savanna Ecosystem. Plant Ecology. Department of Biology, Syracuse University. v.167, p. 319332, 2003. 10.1023/A:1023927512590.

BAILLY, D.; FERNANDES, C. A.; SILVA, V. F. B.; KASHIWAQUI, E. A. L.; DAMÁSIO, J. F.; WOLF, M. J.; CÉSAR, R. M. Diagnóstico Ambiental e Impacto sobre a Vegetação Ciliar da Microbacia do Córrego da Ponte, Área de 
Proteção Ambiental do Rio Iguatemi, MS. Revista em Agronegócios e Meio Ambiente. v.5, n.2, p.409-427, 2012.

BASTOS, F. H. Movimentos de massa no maciço de Baturité (CE) e contribuições para estratégias de planejamento ambiental. 2012. 257f. Tese (Doutorado em Geografia). Universidade Federal do Ceará, Fortaleza. 2012.

BASTOS, F. H.; PEULVAST, J. P. Suscetibilidade à Ocorrência de Movimentos de Massa no Maciço de Baturité Ceará, Brasil. Revista do Departamento de Geografia. USP. v.32, 2016.

BRANDÃO, R. L. Geodiversidade do Estado do Ceará. Fortaleza: CPRM, 2014, 214 p.

BRASIL. Lei Federal $n^{\circ}$ 12.651, de 25 de maio de 2012. Dispõe sobre a proteção da vegetação nativa; altera as Leis $\mathrm{n}$ 오 6.938, de 31 de agosto de 1981, 9.393, de 19 de dezembro de 1996, e 11.428, de 22 de dezembro de 2006; revoga as Leis no 4.771, de 15 de setembro de 1965, e 7.754, de 14 de abril de 1989, e a Medida Provisória no ${ }^{-}$2.166-67, de 24 de agosto de 2001; e dá outras providências. Disponível em: <http://www.planalto.gov.br/ccivil 03/ ato2011-

2014/2012/lei/112651.htm>. Acesso em: 06 de dezembro de 2018.

BRASILEIRO, F. M. G.; SILVA, J. F.; PEREIRA, C. L. G.; PINHEIRO, S. T.; SALES, M. C. L. Diagnóstico dos Impactos Ambientais no Rio Canidé: contribuições teóricometodológicas para a gestão de recursos hídricos no município de Paramotí-CE. Revista Equador. UFPI. v.5, n.4 (Edição Especial 03), p. 75-92, 2016.

BRAZ, A. M.; BARROS, M. H. S.; BRAZ, A. M.; GARCIA, P. H. M. Manejo e capacidade de uso das terras aplicando geotecnologias na bacia hidrográfica do córrego Lajeado Amarelo - Três Lagoas/MS. Revista Cerrados. v.15, n.1, 2017.

CARVALHO, R. G. Análise de Sistemas Ambientais Aplicada ao Planejamento: estudo em macro e mesoescala na região da bacia hidrográfica do rio Apodi-Mossoró, RN/Brasil. 2011, 269f. Tese (Doutorado em Dinâmica Territorial e Ambiental), Universidade Federal do Ceará, Fortaleza, 2011.

COSTA, L. B. Análise e proposta de zoneamento geoambiental da subbacia hidrográfica do riacho Santana, sudoeste do Rio Grande do Norte. 2015. 135f. Dissertação (Mestrado em Organização, Produção e Gestão do Território no Semiárido) Universidade Estadual Vale do Acaraú, Sobral, 2015.

CORRÊA, C. J. P.; TONELLO, K. C.; FRANCO, F. S. Análise hidroambiental da microbacia do Pirajibu-Mirim, Sorocaba, SP, Brasil. Revista Ambiente \& Água. v. 11, n. 4, 2016. Doi:10.4136/ambi-agua.1969.

CRISPIM, A. B.; SOUZA, M. N. Degradação, Impactos Ambientais e Uso da Terra em bacias Hidrográficas: o contexto da bacia do Pacotí/CE. ACTA Geográfica. v.10, n.22, p. 17-33, 2016. ISSN 1980-5772 e ISSN 2177-4307.

CUNHA, S. B.; GUERRA, A. J. T. Degradação Ambiental. In. GUERRA, A. J. T.; CUNHA, S. B. (Orgs). Geomorfologia e
Meio Ambiente. $3^{\circ}$ ed. Rio de Janeiro: Bertrand Brasil, 2000, p.337-379.

CUNHA, T. J. F. Uso atual e ocupação dos solos na margem direita do Rio São Francisco em Municípios do Estado da Bahia. Petrolina: Embrapa semiárido, 2011.

DE JONG, C.; MACHAUER, R.; REICHERT, B.; CAPPY, S.; VIGER, R. An Integrated Geomorphological and Hydrogeological MMS Modeling Framework for a Semi-arid Mountain Basin in the High Atlas, Southern marocco. 2nd international Congress on Environmental Modeling and software. Osnabruck, Germany, June, 2004.

DERÍSIO, J. C. Introdução ao Controle de Poluição Ambiental. $4^{\text {o }}$ ed. São Paulo: Oficina de Textos, 2012.

FERREIRA, C. C.; PIROLE, E. L. Zoneamento ambiental das paisagens: Estudo de caso do Alto curso da Bacia Hidrográfica do rio Sucuriú, Mato Grosso do Sul, Brasil. Revista Boletim Goiano de Geografia. v.36, n.2, 2016.

FREIRE, L. M. Paisagens de exceção: problemas ambientais no Município de Mulungu, serra de Baturité. 2007. 134p. Dissertação (Mestrado em Geografia) Universidade Estadual do Ceará, Fortaleza. 2007.

FREIRES, E. V.; TEIXEIRA, C. P. B.; DUARTE, C. R.; GOMES, D. D. M. Análise da Expansão Urbana no Entorno da APA da Serra de Aratanha/CE. In: I Congresso Nacional de Geografia Física. 2017, São Paulo. Artigo... Campinas-SP: Unicamp, 28 de junho à 02 de julho de 2017, p. 6706-6717. 10.20396/sbgfa.v1i2017.1864.

FREITAS, E. P.; MORAES, J. F. L.; PECHE FILHO, A.; STORINO, M. Indicadores ambientais para áreas de preservação permanente. Revista Brasileira de Engenharia Agrícola e Ambiental. v.17, n.4, 2013.

GHOLAMI, S.; SAADAT, L.; SAYAD, E. Different Microhabitats have Contrasting Effects on the Spatial Distribution of tree Regeneration Density and Diversity. Journal of Arid Environments. Iran. v.148, p. 1-5, 2018. 10.1016/j.jaridenv.2017.10.008.

GIL, A. C. Como elaborar projetos de pesquisas. $4^{\circ}$ ed. São Paulo: Atlas, 2006.

GUERRA, A. J. T.; CUNHA, S. B. Geomorfologia e meio ambiente. 3. ed. - Rio de Janeiro: Bertrand Brasil, 2000.

IDEMA, Instituto de Desenvolvimento Econômico e Meio ambiente. Perfil do seu município. Natal: Rio Grande do Norte 2010. Disponível em: 〈http://www.idema.rn.gov.br〉. Acesso em 10 de junho de 2019.

KLIK, A.; KAITNA, R.; BADRAOUI, M. Desertification Hazard in a Mountainous Ecosystem in the High Atlas Region, marroco. 12th ISCO Conference Beijing. University of Agricultural Sciences Vienna (BOKU), 2002. 
LEPSCH, I. F. Solos do Mundo. In: LEPSCH, I. F. (org.). Formação e Conservação dos solos. São Paulo: Oficina de textos, 2002 p. $87-122$.

LIMA, E. C. Planejamento Ambiental como Subsídio para Gestão Ambiental da Bacia de Drenagem do Açude Paulo Sarasate Varjota-Ceará. 2012. 201f. Tese (Doutorado em Dinâmica Territorial e Ambiental), Universidade Federal do Ceará, Fortaleza, 2012.

LITTLE, J. L.; SAFFRAN, K. A.; FENT, L. Land Use and Water Quality Relationships in the Lower Littler Bow River Watershed, Alberta, Canada. Water Quality Research Journal of Canada. v.38, n.4, p.563-584, 2003.

MARTINS, A. P. F.; TERTO, R. S.; LIMA, J. R.; OLIVEIRA, E. Estudo de Impactos Ambientais na Comunidade Quilombola Serra Feia - Cacimbas, PB. Revista ACSA. PatosPB. v.13, n.2, p.121-129, 2017. ISSN: 1808-6845.

MOLUA, E. L.; LAMBI, C. M. Climate, Hidrology and Water Resources in Cameroon. Environmental Issues: Problems and Prospects. Bamenda: Unique Printers, p. 41-66, 2001.

MOTÉ, F. O.; MARÇAL, M. S.; BONATTO, G. Uso e Cobertura da Terra Associado as Unidades de Relevo e Problemas Ambientais na Bacia do Rio Macaé (RJ). In: VI Simpósio Nacional de Geomorfologia. 2006, Goiás. Artigo... Goiânia-GO, 6 a 10 de setembro de 2006, p. 01-10.

NAIR, P. K. R. Agroforestry. Elsevier LTD. University of Florida, Gainesville, FL, USA, 2005.

NUNES, E. Geografia Física do Rio Grande do Norte. Natal: Imagem Gráfica, 2006.

ODUM, E. P.; BARRET, G. W. Fundamentos de Ecologia. [tradução pégasus sistemas e soluções]. - São Paulo: Cengage Learning, 2015.

OLIVEIRA, F. L.; SILVA, C. A.; SILVA, E. E. S.; ALMEIDA, L. Q. Classificação dos Diferentes Tipos de uso do Solo nos Sistemas Ambientais do Município de Pacotí, Ceará. In: I Congresso Nacional de Geografia Física. 2017, São Paulo. Artigo... Campinas-SP: Unicamp, 28 de junho à 02 de julho de 2017, p. 5525-5533. 10.20396/sbgfa.v1i2017.2235

OLIVEIRA FILHO, G. R. Os Movimentos de Massa na Região Serrana do Estado do Rio de Janeiro em 2011: diagnóstico e proposição de medidas para enfrentamento de desastres ambientais. CES Revista. v.26, n.1, p.149-164, 2012.

QUEIROZ, A. F. Aspectos Pedológicos das Microrregiões de São Miguel, Umarizal e Pau dos Ferros. In: ALMEIDA, J. E.; ALVES, A. M. Zoneamento ecológico-econômico do Alto
Oeste Potiguar: microrregiões de Pau dos Ferros, São Miguel e Umarizal. Mossoró, RN: Queima-Bucha, 2014, p. 31-43.

RIBEIRO, L. E.; BASTOS, F. H. Contexto Geoambiental da Serra do Juá-Conceição, Região Metropolitana de Fortaleza, Ceará. REGNE. v.2, Número Especial, 2016.

RITTER, L. G.; RENZ, V. D.; GARLET, G.; CHAGAS, P.; MANCUSO, M. A.; HASS, A.; CONCEIÇÃO, S. R. Manejo da Micro Bacia do Lajeado Pardo. Holos. v.6, n.31, 2015. DOI: 10.15628/holos.2015.1685

RODRIGUEZ, J. M. M.; SILVA, E. V. A classificação das paisagens a partir de uma visão geossistêmica. Mercator Revista de Geografia da UFC, ano 01, número 01, 2002.

SANTOS, F. A.; AQUINO, C. M. S. Diagnóstico Físico Conservacionista Aplicado ao Estudo da Desertificação nos Municípios de Castelo do Piauí e Juazeiro do Piauí, Nordeste, Brasil. Revista de Geografia. Recife. v.34, n.2, 2017. ISSN 0104-5490.

SILVA, G. C. M. Diagnóstico da Degradação Ambiental no município de Areia Branca-RN por Geotecnologias. 2013, 107f. Dissertação (Mestrado em desenvolvimento e meio ambiente) Universidade Federal do Rio Grande do Norte, Natal, 2013.

SILVA, L. F. T. C.; CASTRO, U. N.; GUERRA, A. J. T.; LIMA, F. S.; MENDES, S. P.; BEZERRA, J. F. R. Degradação ambiental em áreas destinadas à pecuária na sub-bacia hidrográfica do rio Sana, Macaé - RJ. Revista de Geografia (UFPE) v.29, n.1, 2012.

SILVA, R. V. uso e ocupação da margem esquerda do rio paraguai e a percepção ambiental de usuários do município de Cáceres, Mato Grosso. 2011, 109f. Dissertação (Mestrado em Ciências Ambientais), Universidade do Estado de Mato Grosso, Cáceres. 2011.

SOUZA, C. N. Geologia do estremo oeste potiguar - área de Luís Gomes/RN. (Relatório de graduação do curso de geologia). Universidade Federal do Rio Grande do Norte UFRN, Natal, 1984.

SOUZA, R. F.; BARBOSA, M. P.; MORAES NETO, J. M.; MENESES, L. F.; GADELHA, A. G. Vulnerabilidades e Impactos Socioeconômicos e Ambientais em Municípios do Cariri Paraibano. Revista Engenharia Ambiental. v.5, n.3, 2008.

TABARI, H.; AGRAJANLOO, M. B. Temporal Patterno f Aridity Index in Iran with Considering Precipitation and Evapotranspiration Trends. International Journal of Climatology. v.33, p.396-409, 2013. 